Case Report

\title{
IIp 3 deletion syndrome: First case in morocco detected by fish
}

\begin{abstract}
$11 \mathrm{p} 13$ deletion Syndrome or WAGR is an acronym for Wilms tumor, aniridia, genitourinary anomalies and mental retardation; accordingly WAGR syndrome is a rare contiguous gene syndrome characterized by a de novo deletion in the distal band of $11 \mathrm{p} 13$ region. The deletion may involve several neighboring genes, including PAX6 responsible for aniridia and Wilms tumor 1 gene (WT1). Genetic testing using fluorescence in situ hybridization is the best method to detect a specific micro deletion in case a clinical suspicion is indicated. We report here the first Moroccan case recognized as WAGR syndrome at first day of life being confirmed by molecular cytogenetics at 2 years of age. Early confirmation of such a diagnosis is important to provide comprehensive genetic counseling to the family, to set up appropriate treatment and surveillance of the patient, and to enrich genetic data on Moroccan population.
\end{abstract}

Keywords: WAGR Syndrome; FISH; Treatment and Surveillance; First Moroccan Case
Volume I Issue 7 - 2014

\author{
Abdelhafid Natiq, ${ }^{1,3}$ Saadia Amasdl,' Thomas \\ Liehr, ${ }^{4}$ Katharina Kreskowski, ${ }^{4}$ Britta Meyer, ${ }^{5}$ \\ Ilhame Ratbi, ${ }^{2}$ Saaid Amzazi, ${ }^{3}$ Abdelaziz \\ Sefiani ${ }^{1,2}$ \\ 'Departement de Genetique Medicale, Institut National \\ d'Hygiene, Morocco \\ ${ }^{2}$ Centre de genomique humaine, Faculte de medecine et de \\ pharmacie, Universite Mohammed V, Morocco \\ ${ }^{3}$ Faculte des Sciences de Rabat, Universite Mohamed V Agdal, \\ Morocco \\ ${ }^{4}$ Jena University Hospital, Friedrich Schiller University, Institute \\ of Human Genetics, Germany \\ ${ }^{5}$ ZytoVision $\mathrm{GmbH}$, Germany
}

Correspondence: Abdelhafid Natiq, Department of Medical Genetics, National Institute of Hygiene, 27, Avenue Ibn Batouta BP 679, AGdal I I 400 Rabat, Morocco, Tel 00-21 2666067203 , Email abdelnat@yahoo.fr

Received: October 15, 2014 | Published: November 29, 2014

Abbreviations: FISH, fluorescence in situ hybridization; WAGR, wilms tumor-aniridia-genital anomalies-retardation; WT1, wilms tumor gene 1; APGAR, appearance pulse grimace activity and respiration; MRI, magnetic resonance imaging; ACC, agenesis of corpus callosum

\section{Introduction}

Wilms tumor-aniridia-genital anomalies-retardation syndrome (WAGR) called also $11 \mathrm{p} 13$ deletion Syndrome was first described by Miller et al. ${ }^{1}$. It is a rare autosomal dominant disease, characterized by a de novo deletion within the distal band of chromosome 11, sub band $11 \mathrm{p} 13 .{ }^{2}$ Classical features of the syndrome are total or partial aniridia, possibly associated with glaucoma or cataract; besides atypical findings like microphthalmia, corneal anomalies, absent anterior chamber with retinal dysfunction were reported. WAGR is also associated with an increased risk of developing bilateral Wilms tumor in kidney which can occur at any age. Overall in WAGR genitourinary disorders may be highly variable including cryptorchidism (observed in $\sim 60 \%$ of male patients), and in female uterine abnormalities, hypospadias, ambiguous genitalia, streak ovaries, urethral strictures, ureteric abnormalities, and gonadoblastoma; external genitalia are usually normal in females with WAGR syndrome. ${ }^{3}$

Besides mental retardation and behavioral abnormalities are may be observed to different degrees. Neurologic features like hyper or hypotonia, epilepsy, enlarged ventricles and rarely corpus callosum agenesis may be present. Obesity was also reported in several patients with WAGR syndrome. ${ }^{4}$ Craniofacial dysmorphism, hemihypertrophy, growth retardation, scoliosis, kyphosis, polydactyly and congenital diaphragmatic hernia were occasionally described in patients with WAGR. ${ }^{5}$

WAGR is a so-called contiguous gene syndrome where there is a germline based interstitial micro deletion at $11 \mathrm{p} 13$ involving numerous neighboring genes. As disease -associated are regarded especially the PAX6 (ocular development gene, OMIM 607108), and WT1 (Wilms tumor gene 1, OMIM 194070) ${ }^{3}$ as haplo insufficiency of these two genes explain most of the clinical features of the syndrome. Here we describe the first Moroccan WAGR patient with a proven microdeletion of the corresponding critical region in $11 \mathrm{p} 13$.

\section{Case report}

A 2-year-old boy with nephroblastoma, congenital ocular anomalies and developmental delay was referred for medical genetics consultation to National Institute of Health of Rabat, Morocco. He was the second child of a healthy non-consanguineous couple, a 33 year old mother and 38 year old father. The pregnancy has been medically followed. At birth, he weighed 2,001g and the length was $42 \mathrm{~cm}$; his head circumference was $31 \mathrm{~cm}$. The APGAR score was in normal range, however, low facial dysmorphism and a bilateral cryptorchidism were noticed on the first physical examination. On 25 th days of life he was diagnosed with bilateral complete aniridia, bilateral and subtotal glaucoma with slight megalocornea, bilateral microspherophakia, amblyopia, horizontal nystagmus and hypotonia.

At 20 months of age the patient presented an increase of the abdominal volume with pain and fever. Abdominal genitourinary ultrasonographies showed a left renal tumoral process, diagnosed as a nephroblastoma on abdomino-pelvic scan. The staging did not identify other metastatic localizations of the tumor. Later on he had a total left nephrectomy followed by chemotherapy. Brain magnetic resonance imaging (MRI) showed a total agenesis of the corpus callosum.

Clinical examination at 2 years of age showed a growth delay with a weight of $12 \mathrm{~kg}$ ( $25^{\text {th }}$ centile), height of $81.5 \mathrm{~cm}\left(3^{\text {rd }}-10^{\text {th }}\right.$ centile $)$ and an OFC of $47.8 \mathrm{~cm}\left(25^{\text {th }}\right.$ centile $)$. He had no particular facial 
dysmorphic features. However, he presented with developmental delay, could not sit without support, and his speech development was delayed. Informed consent was obtained from the patients parents prior to implementation of a cytogenetic study. According to guidelines in similar cases, high resolution chromosome study at 550 bands level was performed as previously reported and according to the international system for Human Cytogenetics Nomenclature ISCN 2013, ${ }^{6,7}$ but revealed a normal karyotype (Data not shown). Fluorescence in situ hybridization (FISH) using a probe specific for the WAGR-locus in 11p13 (Zytolight SPEC WT1 Dual Color Break Apart Probe, Zytovision, Bremerhaven) (Figure 1) led to the identification of a typical disease causing microdeletion (Figure 2).

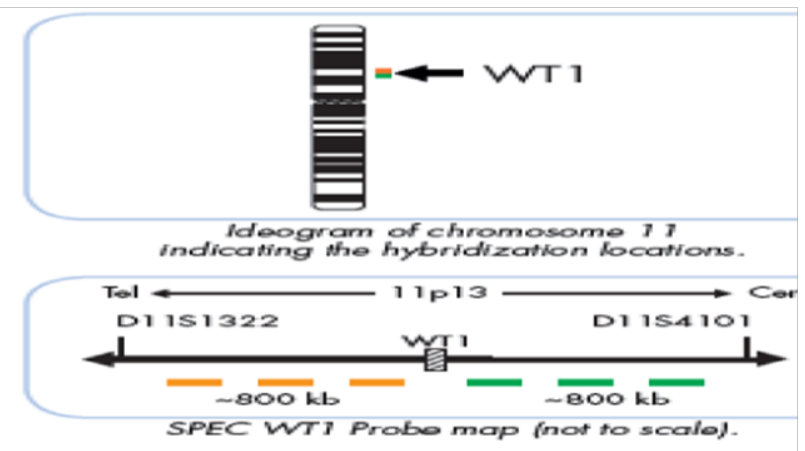

Figure I Schematic representation of chromosome II indicating the hybridization location and SPECWTI probe map.

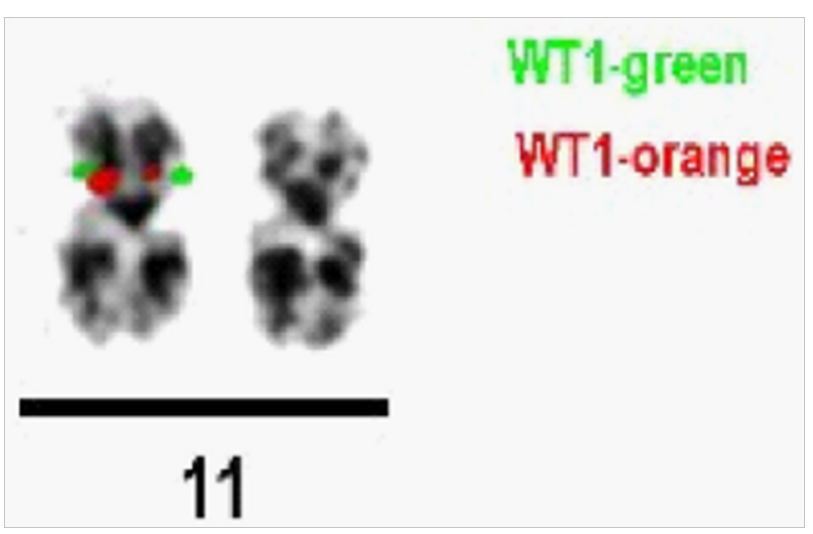

Figure 2 FISH analysis of the I IpI 3 deletion.

Using WTI dual color break apart probe.Arrow indicates the absence of both orange and green signal on specific region of the WAGR-locus in IIpI3.

\section{Discussion}

WAGR is a very rare autosomal dominant disorder with a prevalence of 1/500,000 birth (OMIM 106210). Clinical presentation is variable and may, but must not include aniridia. Such cases are suggested to have an incidence of $1 / 50,000$ to $1 / 100,000 .^{8,9}$ In cases with aniridia, the PAX6 gene is mutated or deleted, which encodes a transcriptional regulator and involved in ocular morphogenesis. The present patient obviously belongs to the larger group of WAGR without PAX6 involvement. ${ }^{10}$

The second common clinical criterion of WAGR is Wilms tumor (WT, OMIM 194070) and was observed in the present case. WT is one of the most common solid tumors of childhood occurring in 1/10,000 cases $^{11}$ and thus accounting for $8 \%$ of childhood cancers. The age of onset is between 3 and 4 years and the majority of cases are diagnosed before 5 years of age. ${ }^{12}$ WT is a developmental malignancy of the kidney which is thought to be related to a persistence of embryonic cells, known as nephrogenic rests. ${ }^{13}$ The WT1 gene is a tumor suppressor gene located in $11 \mathrm{p} 13$, it has a pivotal role in kidney and gonadal development. In WAGR syndrome, the risk for a WT was estimated to be $57 \%{ }^{3}$

Occurrence of genitourinary abnormalities in WAGR as also seen in this case report still remain unclear. Among the suggestions that explain this mechanism, several genes are suggested to be regulated by $W T 1$ including $S R Y .^{14}$ The last criterion of WAGR is intellectual disability and behavioral abnormalities which are highly variable; $70 \%$ of patients have intellectual disability, nevertheless, others can have normal intellect without behavior problems. Even though the patient is still at young age such features also could be observed.

In addition to these classical clinical features of the WAGR, our patient had also agenesis of corpus callosum (ACC); however, this was also already reported in similar cases, e.g. first in 2001 by Yamamoto et al. The presence of ACC associated with DEFECT 11 syndrome suggests the presence of gene(s) responsible for it in the proximal portion of the short arm of chromosome $11 .{ }^{15} \mathrm{ACC}$ is a common brain malformation seen in various etiologies, including associations with structural chromosome rearrangement. ${ }^{16}$

Overall, the present patient was already according to clinical signs and symptoms very likely to suffer from WAGR. Still, this needed the confirmation of diagnosis by FISH. After this was done, here as first case in Morocco, the patient was treated following the recommendation for health supervision for child with WAGR. Treatment was multidisciplinary, including surgery and chemotherapy for WT, nephrectomy and surgical treatment of cryptorchidism. Regular examination and symptomatic measures for aniridia, surgical cure for urogenital anomalies and prevention of secondary complications are now performed due to solid molecular diagnostics. Also monitoring of visual function, regular renal ultrasound examinations and of renal function were recommended.

In conclusion, we report the first clinical and cytogenetic description of a Moroccan patient with WAGR syndrome. The confirmation by FISH of a deletion $11 \mathrm{p} 13$ help to provide an appropriate therapeutic strategy and best follow up of the patient, make an adequate genetic counseling to family and enrich genetic data of Moroccan population.

\section{Acknowledgements}

The authors would like to gratefully acknowledge the patient and her parents for their collaboration.

\section{Conflicts of interests}

None.

\section{Funding}

None.

\section{References}

1. Miller RW, Fraumeni JF, Manning MD. Association of Wilms's tumor with aniridia, hemihypertrophy and other congenital malformations. $N$ Engl J Med. 1964;270:922-927.

2. Riccardi VM, Sunjansky E, Smith AC, et al. Chromosomal imbalance in Aniridia-wilms' tumor association 11p interstitial deletion. Pediatrics. 1978;61(4):604-610. 
3. Fischbach BV, Trout KL, Lewis J, et al. WAGR syndrome: A clinical review of 54 cases. Pediatrics. 2005;16(4):984-988.

4. Bremond-Gignac D, Crolla JA, Copin H, et al. Combination of WAGR and Potocki-Shaffer contiguous deletion syndromes in a patient with an 11p11.2-p14 deletion. Eur J Hum Genet. 2005;13(4):409-413.

5. Simons A, Shaffer LG, Hastings RJ. Cytogenetic nomenclature: Changes in the ISCN 2013 compared to the 2009 edition. Cytogenet Genome Res. 2013.

6. Aboussair N, Jaouad IC, Dequaqui SC, et al. Cytogenetic analysis of 5572 patients referred for suspected chromosomal abnormalities in Morocco. Genet Test Mol Biomarkers. 2012;16(6):569-573.

7. Scott DA, Cooper ML, Stankiewicz P, et al. Congenital diaphragmatic hernia in WAGR syndrome. Am J Med Genet A. 2005;134(4):430-433.

8. Manoukian S, Crolla JA, Mammoliti PM, et al. Bilateral preaxial polydactyly in a WAGR syndrome patient. Am $\mathrm{J}$ Med Genet A. 2005;134(4):426-429.

9. Crolla JA, Cawdery JE, Oley CA, et al. A FISH approach to defining the extent and possible clinical significance of deletions at the WAGR locus. J Med Genet. 1997;34(3):207-212.
10. Walther C, Gruss P. Pax-6, a murine paired box gene, is expressed in the developing CNS. Development. 1991;113(4):1435-1449.

11. Stiller CA, Parkin DM. International variations in the incidence of childhood renal tumours. Br J Cancer. 1990;62(6):1026-1030.

12. Breslow N, Beckwith JB, Ciol M, et al. Age distribution of Wilms' tumor: report from the National Wilms' Tumor Study. Cancer Res. 1988;48(6):1653-1657.

13. Hennigar RA, O'Shea PA, Grattan-Smith JD. Clinicopathologic features of nephrogenic rests and nephroblastomatosis. Adv Anat Pathol. $2001 ; 8(5): 276-289$.

14. Matsuzawa-Watanabe Y, Inoue J, Semba K. Transcriptional activity of testis-determining factor SRY is modulated by the Wilms' tumor 1 gene product, WT1. Oncogene. 2003;22(39):7900-7904.

15. Yamamoto T, Akaboshi S, Ninomiya H, et al. DEFECT 11 syndrome associated with agenesis of the corpus callosum. $J$ Med Genet. 2001;38(2):e5

16. O'Driscoll MC, Black CG, Clayton-Smith J, et al. Identification of genomic loci contributing to agenesis of the corpus callosum. Am J Med Genet A. 2010;152A(9):2145-2159. 